\section{Estuary Channels and Embankments}

IN the Vernon-Harcourt Lecture delivered at the Institution of Civil Engineers on December 8, Dr. Brysson Cunningham discussed "Estuary Channels and Embankments". The two chief objects of the engineering treatment of estuaries are the regulation and improvement of the navigable channel and the protection of adjacent low-lying land from tidal inundation. From the point of view of navigation, defects arise from three main causes : (1) a shifting, unstable channel ; (2) a narrow bed, with inadequate depth of water; and (3) a bar. In carrying out estuary training works for the removal or amelioration of the first defect, certain principles have to be observed in order to avoid risks and possibilities involved in the confinement of the stream within a definite course. The design of different types of wall was considered by Dr. Cunningham. As regards shallowness of the river bed, the principal remedy, although not of a permanent nature, is dredging by means of floating plant of various types. The cause and origin of bars were next discussed, and the peculiar conditions attached to dredging operations in exposed situations were set out with particulars of some of the latest and largest dredgers engaged on that class of work. Dealing with estuary embankments, Dr. Cunningham pointed out that in the case of the Thames alone, there are more than 40,000 acres of serviceable marshland, utilized for a variety of purposes, which have to be protected at high water in this way, while, in the maritime provinces of Holland, whole districts lie so low as to be permanently below sea-level. The embankments on the Thames, the Trent and at the mouths of the Schelde and the Maas were illustrated and the nature of their construction explained, including the design of sluices for dealing with the drainage of inland water.

\section{Television on a Large Screen}

According to reports in The Times of December 8 and 10, two demonstrations have been given recently of the reproduction of the London television programmes on a large screen. In the first case, $\mathrm{Mr}$. J. L. Baird showed the B.B.C. television programme on a large cinema screen. The receiver utilized a eathode ray tube, on the luminescent screen of which a small picture, 2 in. square, was first formed. This was then projected optically on to the large screen to give a picture about $8 \mathrm{ft}$. by $6 \mathrm{ft}$. At all times the picture, it is stated, was quite clear as viewed from both the front and the back of the theatre; the focus was good and there was never sufficient interference to disturb the enjoyment of the audience. The second demonstration was given by Messrs. Scophony Ltd., using the pioneer optico-mechanical methods developed by that company. In this case, two receivers were available, one giving a screen picture $6 \mathrm{ft}$. by $5 \mathrm{ft}$. suitable for a medium-size hall, and the other being a home receiver providing a picture $2 \mathrm{ft}$. square. The first receiver was demonstrated to a large audience, who saw a very acceptable reproduction of the afternoon television programme. The pictures were free from flicker and were bright enough to be seen in comfort by everyone present. It seems likely that these two demonstrations will mark a new stage in the progress of the technique of television reproduction.

\section{Thermionic Valve Data}

THE modern thermionic valve has now become of world-wide importance, not only in connexion with radio broadcasting, but also in its many applications in scientific and commercial instruments, and in industrial processes. Unfortunately for those who have to make constant use of valves of the usual receiving type, their popularity and rapid advances during the past decade have resulted in a multifarious range of valves for different purposes. In spite of several earnest attempts, no satisfactory means of elassifying these valves has been standardized, and the various manufacturers have accordingly adopted different and arbitrary codes for designating the types of valves which they supply. Amidst this confusion and in the absence of adequate co-operation between manufacturers in different countries, it is natural to find that the number of types is constantly increasing and is now quite unnecessarily large. Pending the time when more uniformity is arrived at, however, the Wireless World has been fulfilling a useful public service for the past ten years by issuing a list of valve types with the appropriate technical data. A search through these lists reveals in a striking manner not only the growth in the number of valves, but also the increasing amount of information which is needed about a valve in order to select a suitable type for any purpose. The issue of the Wireless World of November 25 contains the latest of these lists in the form of a nineteen-page supplement. The data here provided cover more than 900 current valve types, both British and American, as many as fourteen numerical characteristics being given for some of the valves. A useful guide to valve bases is also provided. Such a publication cannot fail to be of great utility to all scientific and technical workers who make use of the modern thermionic valve.

\section{Accessions to the British Museum (Bloomsbury)}

AMONG the accessions to the collections of the British Museum (Bloomsbury) announced in December are a number of antiquities from the Near East and Egypt. Of these, among the more noteworthy are those obtained by Mr. M. E. L. Mallowan's excavations of last season on sites in northern Syria. Clay tablets from Chager Bazar, dating from about 2000-1900 B.C., deal with accounts, mostly relating to corn. Although the names of the months are Babylonian, the tablets appear to indicate that the district was then under the dominion of Assyria. Objects from another site, Brak, are of considerable importance in the prehistory of western Asia, as they include black-on-white pottery, similar to that found by Sir Leonard Woolley at Atchana near the mouth of the Orontes, and bearing out his conclusion as to the international importance of that region as an emporium linking the Mediterranean and the (Continued on page 1055) 